\title{
Teenagers, Digital Media, and Language Development: An Exploration of Potential and Challenges in Promoting English Skills
}

\author{
Norma Novianto ${ }^{1}$, Dewi Puspitasari ${ }^{2}$, Chusna Maulida ${ }^{3}$ \\ 1,2,3 IAIN Pekalongan, Pekalongan, Indonesia
}

(2) nargie8181@gmail.com

\begin{abstract}
Digital media has a significant role in the development of English for teenagers. The rapid development in digital technologies enables the teacher to be creative and innovative in teaching a second language, it can be used as a tool to enhance language learning, through increasing the opportunities for contact with native speakers and input from the target language. The research design used in this study was a literature study and collected data through navigating some relevant studies relating to social media. The researchers chose and analyzed the information about the potential and challenges of digital media in promoting English language development for teenagers. The challenges of fostering English language development through digital media in teenagers based on literature reviews are teachers' problems. Digital media is a potential aid of promoting English language development in teenagers depends on the ability of teachers to minimize the challenges.
\end{abstract}

\section{KEYWORDS:}

English for teenager;

Digital media;

Language development

\section{Introduction}

In Indonesia, teaching English to teenagers is a part of curriculum. It is based on Ministerial Decree No.22 Year 2006, dated May 23rd, 2006, which states that English subject can be given to secondary students as a local content. This decree results in the existence of English in secondary schools which is taught starting from the fourth grade for two credit hours every week. Teaching teenagers are sometimes complicated as they are in the transition of children to the next level, adolescent. teenagers are often described as learners having complex problems 
for their teachers as they are problematic to deal with. Paying attention to their interest is required (Saumel, 2014). Building rapport is highly recommended as by this the relationship among teacher and them will be improved. Teaching them means teachers should consider young learners' stage, hence in this study we consider children's interesting activities to be further implemented as ideas to conduct in classrooms.

In teaching English to elementary school students, teachers deal with young learners whose characteristics are different from adult learners. Apart from the difference, a study of Wilkins, Boman, \& Mergler (2015) reported that the combination of four positive character traits, gratitude, optimism, zest and persistence, are found to relate to the higher levels of students pro-social behaviour and their positive engagement in schools. For secondary school students, their cognitive developments lay on concrete operational stage. In this stage, children begin to think logically and use their experience to solve problem. Nevertheless, they are only able to solve problem which are applied to concrete examples and objects in real. Another characteristic is attention span. Attention span is defined as the amount of time in seconds the child remains on task without distraction. In learning, attention span can be seen when children pay attention to the teacher or focus on the learning. Musthafa (2010)) argues that unlike adults who have long attention span, children only have attention span less than 15 minutes.

An interesting media and appropriate method is needed in order to teaching English to teenagers effectively. They have their own characteristic. Their cognitive developments lay on concrete operational stage. In this stage, they begin to think logically and use their experience to solve problem. Nevertheless, they are only able to solve problem which are applied to concrete examples and objects in real life. Media used in the teaching learning activity will keep the learner focus on the teacher, thus the classroom will be on teacher's control. The media used should be effective and interesting. The use of effective and interesting media in teaching can help the students understand the material easily.

Some previous research dealing with teenagers and young learners are taken as samples. The first to consider is the class preparation. Dealing this, Nurasiah 
(2017) claimed in her study that the English teacher at SMP Nurul Quran made fairly good preparations before teaching English including designing her syllabus and lesson plans, preparing teaching materials, and providing teaching media. This teaching preparation was fitted to the curriculum applied at the school namely the combination of the KTSP and Islamic Character Based curriculum. The lesson plans were carefully designed to provide easy and fun activities that were suitable for students at that level. The activities presented in the classroom were based on what was stated in the lesson plan. The activities were procedural and met the level of the students. The teaching methods applied in the classroom were various such as Cooperative Learning, STAD, CTL, and others. The teacher also designed the learning fun and interesting by teaching English through games such as Simon Says, Scrabble, Guessing, etc. Cooperative interactions took place in the classroom where the students appeared to be free to speak and to ask questions. The study reported that there were several problems in conducting the teaching such as the problems of joint curriculum, syllabus design, lesson plan, problems of two students with special needs, problem with noisy classes and students' discipline, problems with calling for students' attention and problems with classroom size. Albeit these complications, the teacher was capable to deal with them. The key was the good class management to cover the problems she faced in the classroom.

Sari (2020) in her study Competitive storytelling: a competition to combat Covid 19 wrote an online storytelling competition to engage isolated Indonesian students and their teachers to communicate and share ideas during COVID-19. The use of digital technology facilitated these students to be actively learning English in pandemic apart the fact of anxiety and negative emotional wellbeing amidst the pandemic situation.

\section{RESEARCH METHODOLOGY}

The research design used in this study was a literature study. The researchers in this stage collected data from relevants articles. We chose and analyzed the information about the potential and challenges of digital media in promoting English language development for teenagers. The data were collected in the form of words rather than in numbers. 
As teenagers are in the transitional stage of children and adults, we considered any relevant learning materials to be presented as the data. This is expected to enrich the empirical data to be later implemented by teachers teaching teenagers as the rarely found materials.

\section{Finding}

The rapid development in digital technologies enables us to be creative and innovative in the way that we teach second languages. It can be used as a tool to enhance language learning, through increasing the opportunities for contact with native speakers and input from the target language. This interactive exchange and experience with native speakers facilitates learning the language (vocabulary and grammar) as well as cultural knowledge and competency associated with using the language to communicate effectively and appropriately. Moreover, this experience broadens and deepens students as well as teacher's knowledge and understanding of the different cultures and languages.

\section{Discussion}

\section{The potential of digital media in promoting English language development in teenagers}

New technologies can be used to increase student motivation and engagement in the second language learning classroom. Typically, students use a variety of technologies while involved in everyday activities at home. This is one reason why we need to also include these technologies in the classroom. One technology that has proved popular and an effective tool in teaching/learning in the second language classroom is the Interactive Whiteboard (IWB). The visual aspect of the IWB appears to be the primary reason for active motivated engagement in the learning process. The opportunity that it gives students to present and discuss their work has been found to improve attention and engagement in the learning process. This type of technology can be used to provide opportunities for students to actively engage in different activities for different purposes. Additional technologies can also be used in language learning activities including email, 
Apple or Android apps, and social media applications such as Skype, Facebook and YouTube channels if available (Betcher \& Lee, 2009).

However, if these technology supports are not available, we might consider available resources found in teenagers' daily life. One example is by considering game to be used as teaching activity. The use of virtual worlds such as Minecraft has become popular in teaching/learning languages, particularly with adults but also with older children. The activities and goals involved in the use of these technologies can be organised so that they involve collaborative learning between peers. For younger children, electronic books and games can be of great benefit. These types of activities can be projected onto the interactive whiteboard so that the whole class or groups of children can be actively engaged and/or they can be used by individual children on portable tablets so that the content can be learned and revised.

However, it is important to note that teachers need to be provided with support and training to use the technology to mediate pedagogical practices as these technologies are merely useful tools to augment teaching and learning in the language classroom. As Betcher and Lee (2009) point out, teacher needs to understand how to use these technologies in creative and meaningful ways to actively engage children in the learning process. This is in line with teenager's psychological condition in Saumel (2019) that it is important to accomodate their choices in the language classroom. It is stated that teacher may not just let students choose what they want to do, but teacher should refer to choices as planed strategy in conducting a learning moment. What is needed to do at the first stage is by identifying the objective of the task that will be given. After the main objective is clear then a teacher should consider that there are various ways to achieve the objective. This "choice" fits in the task types, tools to be used during the process, the ways of presenting the material, and many others. In order to children can achieve in school, these teenagers must be educated by applying the right approach. Curiosity, creativity, independence, cooperation, and perseverance are some of the approaches used to improve learning and initial development. The approach to learning by playing can be done using a digital media, namely by utilizing gadget technology or mobile devices that are currently developing. Again, 
a teacher should consider about "choice" as explained before. A gentle reminder is that the use of digital media should be supervised by parents or adults, especially concerning to internet connection. By internet, there is no border in learning as they may surf related materials in cyberspace. A student wants to know the images of another cultures without having to visit the area s/he can observe them through online pictures or video. In this pandemic, particularly, the internet connection enables them to navigate without having to visit a real place for instance a museum or zoo. Again, the point is ethical support in the use of technology. This is in line to a study of Wong, Ho, and Chen (2015) that parenting support is needed in the use of internet. From a survey of 796 low-income families and 799 non-low-income families, the study indicated that Shanghai parents are very confident in monitoring their children's use of the Internet, allowing them to benefit from the internet while shielding them from any potential risks. The results of the study also indicate that the trend of authoritarian parenting style, greater participation of parents in children's online activities and a positive attitude towards the Internet are factors linked to parenting supervision, which are especially significant for parents in the lower socio-economic strata. Reflected from this study, we may mirror to Indonesian's case to adopt the similar act, to consider the implementation but be alert on the risk as well.

Some websites to take into account are "BBC", "lyrics training", "English attack", "Youtube", etc. In BBC, for instance teachers may adjust to certain videos and available instruction. 


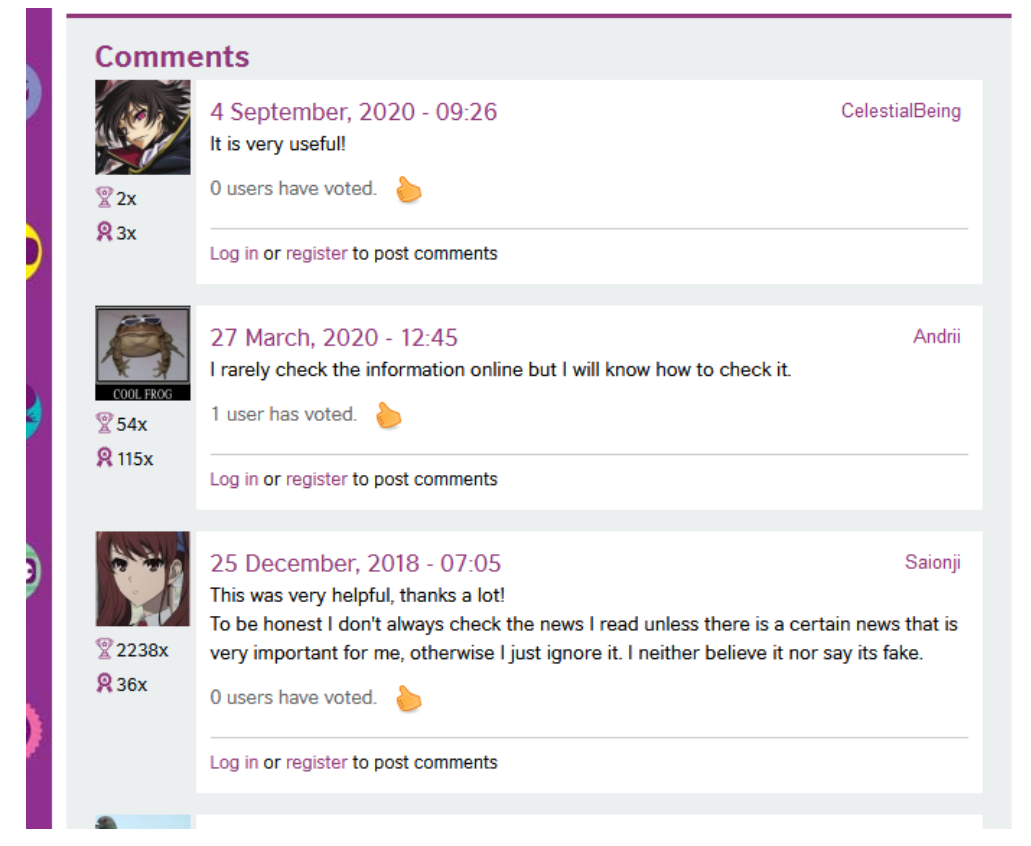

Picture 1: A Respond to Video

Source:https://learnenglishteens.britishcouncil.org/study-break/video-zone/five-ways-spot-fake-news

Picture 1 is an example of the integration of literacy and language learning. Relating to the chance of integration, digital literacy may also help students in the integrated knowledge. Learning this does not require special recognition software, but students can also be encouraged to identify important issues by such videos relevant to current conditions. Students' participation in engaging in learning exercises is when they are asked to pay attention to the video and then leave feedback. Particular activities that have not been done before are developing a new learning environment so that any assignment provided by the teacher is often carried out by the students. The interest of students is due to the concentration of students in acquiring material and their particular attention to learning. As a result, the learning environment is encouraging and students are no longer crowded in the classroom. It can be said that the use of multimedia can solve learning problems for students, such as concentrating on attention, building interest, and even creating a favorable learning atmosphere.

Another website as a source of learning relates to student hobby. Considering that most teenagers enjoy music, teachers have a chance to request an application that can be accessed online. An idea of this may be in the form of a lyp-sync, sing 
along popular songs. In lyrics training.com, students can listen to songs, learn languages while filling gaps while listening. Again the word choices can be made here, since there are numerous songs of every type to choose from.

In another source, Netflix students can watch movies with subtitles in English, to get used to listening to a variety of different accents and dialects in English. Teachers have the potential to apply this to the concept of becoming a dubber. Another activity to ponder is teacher may ask students to create "thought bubles". This idea can be taken from relevant learning sources. Thomson (2019) wrote that a teacher may ask his/her students to choose one wow moment from films they watch. The following activity would be have them develop a phrase or series of phrases to insert into the episode at crucial moments, like: "I can't believe he/she just did that!" or "This is boring". This can be applied as fun activity to handle, especially in the pandemic. Another source is "English Attack." Teenagers will be able to watch movie clips and TV shows. They can watch movie clips and answer questions about understanding, fill in the blanks in the script, and use new words in games. At react.com, students can get movies from the YouTube channel of American teens.

"Choices" can be used as students can respond to music, videos, food, and a whole host of other items. Even if students love to set up their own YouTube channel, teachers can invite them to create content by adapting to the inspiration model. They can show off their dance skills, fashion or make tips for viewers around the world, or make short videos of their favorite hobbies. This will be a contextual teaching, learning English while pursuing one's own hobby.

In 2007, the British Council conducted market research into how the media and Internet has affected the preferred learning styles of young people wanting to learn English around the world including Indonesia). The results of this research $69 \%$ of learners around the world said that they learned most effectively when socializing informally. The result suggests that students learn best from their friends and family. Perhaps that is not so surprising. The things we learn from our loved ones are often more immediately relevant to our lives than what we learn from a teacher in a classroom. Also, when we are relaxed (such as when we are at home or in a café), then we are more open to suggestions and new ideas. Since 
the work they do is self-directed and student centered, they can choose what they want to work on and the pace at which they work. This makes it even more motivating and contributes to the other advantages. Furthermore, they learn more easily. Learning through the use of new media enables the students to learn via many "channels". They come into contact with audio, visual and many more inputs. Pupils learn actively, they have to do something themselves. This trains their social, pragmatic, and cognitive skills. Reading interesting info they have found on the Internet can mediate their language skills. It is not only reading but can be integrated to other integrated elements.

The importance of taking granted Web 2.0 is evidenced by Halim and Hashim (2019) who stated that technology is no longer serve as "alien" in the growing information and communication technology (ICT) era. Integrating technology into the teaching and learning process is seen as vital and necessary in the way it provides more effective learning to learners and in the development of high-quality human resources with 21 st century skills. It is important to integrate technology into the classroom, including through the use of web 2.0 technology. Furthermore, Web 2.0 is part of the student's everyday life. Working at home on school projects with blogs and so on is very natural for them and thus, no artificial forced project. The students can work whenever they want to. They are not forced to follow a certain schedule. As a teacher, it is very easy to start a project since there is so much to find on the Internet. He can search for useful websites and provide these to the students to get them started. While using Web 2.0 services, the pupils improve their skills to work with these services, that is their media and method competence is improved. This could come in very handy for them later jobs and their life in general.

Another potential activity to conduct is students' digital media creation. A study by DeHaan (2011) reported the similar activity when games are considered as learning media. deHaan mentioned that there was high attention given to digital games in education; though the focus were on general education or language and literacy development of native speakers. He narrated game design and game magazine creation as action research projects to guide students to create games 
and game-related media, and at the same time to improve language skills (both spoken and written ones).

\section{The challenges of fostering English language development} through digital media in teenagers

\section{a. Teachers' Problems in Selecting and Using Instructional Media}

Despite the fact that "choices" are suggested to tailor students' need, there is evidence showing teachers' difficulties in choosing appropriate method to teach. Based on the research done by Wildan (2013), problems were encountered by the teachers not only in using instructional media but also in selecting them. In selecting instructional media the problems encountered by the teachers were limited time, limited cost allocation, availability of instructional media, appropriateness of instructional media, and teachers' negative belief towards instructional media.

Problems were also experienced by the teachers in the process of utilizing media. The teachers often encountered technical problems, for instance running out of supply and the dysfunction of high-tech instructional media used. The last was personal problem. It dealt with the difficulty experienced by the teacher in explaining content in the instructional media

\section{b. Problem with Curriculum, Syllabus Design, and Lesson Plan}

Research that found At Nurul Quran Character Based Islamic School, English syllabus and lesson plan were oriented on the combination of KTSP and Islamic character curriculum. The teacher admitted that this combination, gave her problems about how and where to put the character points in the lesson plans, as demanded by the Islamic character curriculum. This, she said, was due to the absence of a standard form of lesson plan from the school.

\section{c. Problem with Students with Special Needs}

The researcher also found that the teacher had problems with two autistic students, one in class 1 and one in class 3 . These two students had learning problems such as difficulty in concentrating on study and writing, difficulty to focus, to understand the lessons and to finish their tasks. They sometimes made noises by hitting their wok table, crying out, screaming, and disturbing their school 
friends. The teachers tried to handle and help these students, but it cost a lot of time and as a result the teachers could not focus on the other students. The other students were disturbed by this phenomenon.

Eventually the English teachers worked with the class teachers to seek a solution and it was decided that each of those students needed a partner teacherstudent. The parents were then told that their children needed help from a partner teacher and it was their responsibility to find these partners. These partner teachers then sat beside each of these students, personally helping them to understand the lesson, and to do their work. Each of them accompanied their student from the beginning until the end of the school each day. It was observed that these partner teachers gave a great contribution to help the teacher handle these students and to keep these two students busy working on their tasks so that they did not make trouble anymore.

\section{d. Problem with Noisy Classes and Student Discipline}

In almost all the classes, the teachers had problems with noisy classes and lack of discipline. Especially in the beginner classes, the students chatted, walked around, played, sang, laughed, came to friends' seats and disturbed their friends. Realizing this, the teacher would get up and calm the class down. She would raise her voice and then lower her voice and then ask them to quiet down, to sit back in their seats, and to behave well.

The researcher observed that the class started to get noisy when some of the students had finished their work early so that they became bored waiting for the teacher to check the work of their friends, and that some students were not doing their work at all. So, there was a mixture of diligent and of lazy students with nothing to do.

This perhaps happened because their classes began after midday so that these students already felt tired and bored. To overcome this, the teacher usually used group activities. She put her students into small groups and each group was given a task to discuss a question. This made the students interested and challenged.

\section{e. Problems with Classroom Physical Size}


While observing the beginner classes, the teacher could not move around the class easily because the physical size of the classroom was too narrow so most of the time the teacher just stood in front of the class. Sometimes she moved around the classroom but she could not reach the students sitting at the very back of the class. However, she continued to pay attention to the whole class.

The number of students in each class was 25 to 27 students. In grades 1 to 3 , there were 8 to 12 students that were sitting on the floor with a long table in front of them that they had to share, while the other students were sitting on chairs with one table for each. However, the classrooms for grades 4 to 6 were bigger in size and the teacher could move around easily.

\section{References}

Betcher, C., \& Lee, M. (2009). The Interactive Whiteboard Revolution: Teaching with IWBs. Melbourne: ACER Press.

DeHaan, J. (2011). Teaching and Learning English through Digital Game Projects. Digital Culture \& Education, 3(1), 46-55. Retrieved from http://www.digitalcultureandeducation.com/cms/wpcontent/uploads/2011/04/dce1046_dehaan_2011.pdf

Halim, M. S. A., \& Hashim, H. (2019). Integrating Web 2.0 Technology in ESL Classroom: A Review on the Benefits and Barriers. Journal of Counseling and Educational Technology, 2. https://doi.org/https://doi.org/10.32698/0381

Musthafa, B. (2010). Teaching English to Young Learners in Indonesia: Essential Requirements. Educationist Journal, 4(2), 120-125.

Nurasiah. (2017). Teaching English to Young Learners: A Case Study at Nurul Quran Islamic School Aceh Besar. English Education Journal (EEJ), 8(1).

Sari, D. R. (2020). Competitive Storytelling. Retrieved from https://www.etprofessional.com/competitive-storytelling

Saumel, V. (2019). What are Your Top 5 Tips for Teaching Teenagers? Retrieved from https://www.teachingenglish.org.uk/blogs/vicky-saumell/what-areyour-top-5-tips-teaching-teenagers-vicky-saumell

Thomson, M. (2019). Netflix and Learn - Six Ways to Teach English Language Skills with Television. Retrieved from https://www.britishcouncil.org/voicesmagazine/teach-english-language-skills-television

Wildan, N. A. (2013). Media in Teaching English to Young Learners: A Case Study in Elementary Schools in Kuningan. Journal of English and Education, 1(1), 196-205.

Wilkins, B., Boman, P., \& Mergler, A. (2015). Positive Psychological Strengths and 
School Engagement in Primary School Children. Cogent Education, 2(1). https://doi.org/10.1080/2331186x.2015.1095680

Wong, Y. C. W., Ho, K. M., \& Chen, H. (2015). Internet Supervision and Parenting in the Digital Age: The Case of Shanghai. Open Family Journal, 7, 112.

Retrieved from https://openfamilystudiesjournal.com 
This page intentionally left blank 